\title{
Efficacy of vonoprazan for 24-week maintenance therapy of patients with healed reflux esophagitis refractory to proton pump inhibitors
}

\author{
HIDEKI MIZUNO, KAZUTOSHI YAMADA, KEIJI MINOUCHI, \\ SHINJI KAMIYAMAMOTO and YOSHINOBU HINOUE \\ Department of Gastroenterology, Toyama City Hospital, Toyama 939-8511, Japan
}

Received November 2, 2017; Accepted November 30, 2017

DOI: $10.3892 /$ br.2017.1035

\begin{abstract}
The aim of the present study was to evaluate the efficacy of a potassium-competitive acid blocker (P-CAB), vonoprazan, for the maintenance therapy of healed reflux esophagitis (RE). A total of 60 patients were enrolled in this open-label, single-center, prospective study. All patients were diagnosed with RE with a frequency scale for the symptoms of gastroesophageal reflux disease (FSSG) total score $\geq 8$ following treatment with standard proton pump inhibitors (PPIs) for a minimum of 8 weeks. Standard PPI treatment was switched to vonoprazan $20 \mathrm{mg}$ once daily for 4 weeks. A total of 52 patients, who had no endoscopic evidence of erosive esophagitis following vonoprazan treatment, received maintenance therapy with vonoprazan $10 \mathrm{mg}$ once daily for 24 weeks. Symptoms were evaluated using the FSSG and Gastrointestinal Symptom Rating Scale (GSRS). Upper gastrointestinal endoscopies were performed following 24 weeks of maintenance therapy. The primary endpoint was to determine the proportion of patients who exhibited maintenance of healed RE refractory to PPIs following 24 weeks of maintenance therapy with vonoprazan $10 \mathrm{mg}$ once daily. Secondary endpoints included evaluation of the proportion of patients with symptomatic non-relapse at 24 weeks. Maintenance therapy with vonoprazan $10 \mathrm{mg}$ once daily prevented relapse of esophageal mucosal breaks in $37 / 43(86.0 \%)$ patients at 24 weeks. However, the number of patients with symptomatic relapse was $1(1.9 \%)$ and $4(7.7 \%)$ at 4 and 8 weeks, respectively. A total of 4 patients were withdrawn due to loss to follow-up. At the end of the 24-week maintenance period, the symptomatic non-relapse rate for acid reflux-associated
\end{abstract}

Correspondence to: Dr Hideki Mizuno, Department of Gastroenterology, Toyama City Hospital, 2-1 Imaizumihokubu-machi, Toyama 939-8511, Japan

E-mail:hmizuno@tch.toyama.toyama.jp

Key words: vonoprazan, gastroesophageal reflux disease, reflux esophagitis refractory to proton pump inhibitors, maintenance therapy and dysmotility symptom FSSG scores were 86.5 and $80.8 \%$, respectively. Furthermore, the symptomatic non-relapse rate for reflux, abdominal pain, indigestion, diarrhea, and constipation GSRS scores at 24 weeks were 86.5, 80.8, 75.0, 71.2 and $76.9 \%$, respectively. No serious adverse events were reported during the study. The mean gastrin level was $1,059 \mathrm{pg} / \mathrm{ml}$. In conclusion, the results of the present study indicate that vonoprazan $10 \mathrm{mg}$ once daily is effective for 24-week maintenance therapy of healed RE refractory to PPIs.

\section{Introduction}

In recent decades, the prevalence of gastroesophageal reflux disease (GERD) has increased in Japan (1). This may be attributed to an increase in gastric acid secretion, a decreased prevalence of Helicobacter pylori infection, novel techniques that allow more sensitive detection and diagnosis of GERD, and the amendment of endoscopic finding criteria according to the modified Los Angeles (LA) classification (2,3). The occurrence of GERD symptoms, including heartburn and acid reflux, at least once a week may considerably affect the quality of life (QoL) of patients with GERD (4-7). As such, the clinical practice guidelines for GERD established by the Japanese Society of Gastroenterology emphasize the importance of achieving complete resolution of symptoms (1). GERD is classified into two categories: Non-erosive reflux disease (NERD) and erosive esophagitis (EE) (8).

Proton pump inhibitors (PPIs) are recommended as the first-line treatment for GERD as they are potent inhibitors of gastric acid secretion $(1,4)$. However, a previous study reported that $40-50 \%$ of patients with NERD and $6-15 \%$ of those with EE were refractory to PPIs treatment (9). In a recent multicenter prospective study from Japan, the endoscopic healing rate of standard-dose PPIs was $\sim 70 \%$ in patients with reflux esophagitis (RE) of LA grade $\mathrm{C}$ and $\sim 60 \%$ in patients with RE of LA grade D (10). Due to these low healing rates, many patients receiving the current standard treatment are not satisfied with their gastrointestinal QoL (10).

Vonoprazan is a novel potassium-competitive acid blocker (P-CAB), part of a new class of gastric acid-suppressant agents. Similar to PPIs, P-CABs inhibit gastric $\mathrm{H}^{+}, \mathrm{K}^{+}$-adenosine triphosphatase (11). However, unlike PPIs, P-CABs inhibit 
enzymes in a $\mathrm{K}^{+}$-competitive and reversible manner $(11,12)$. Vonoprazan is stable in gastric juice, has a quick action and its effect lasts for a long time (13-15). Vonoprazan undergoes substantial metabolic elimination independently of CYP2C19 polymorphism (15). Therefore, the onset of the acid-inhibitory effect of vonoprazan is more rapid than that of esomeprazole in healthy Japanese adult male volunteers with the CYP2C19 extensive metabolizer genotype (15). In a phase 3 clinical trial, the endoscopic healing rate of RE following treatment with vonoprazan $20 \mathrm{mg}$ for 8 weeks was $99 \%$ (16). Recent studies have revealed that vonoprazan $20 \mathrm{mg}$ is effective for a majority of Japanese patients with RE refractory to PPIs (17-19). However, to the best of our knowledge no studies have evaluated the clinical value of maintenance therapy with vonoprazan $10 \mathrm{mg}$ in patients with RE.

The aim of the present study was to evaluate the efficacy of vonoprazan $10 \mathrm{mg}$ for maintenance therapy of healed RE refractory to PPIs. The primary goal was to determine the proportion of patients who had maintenance of healed RE refractory to PPIs following 24 weeks of maintenance therapy with vonoprazan $10 \mathrm{mg}$. The secondary goal was to evaluate the proportion of patients with symptomatic non-relapse at 24 weeks.

\section{Materials and methods}

Study design. This open-label, single-center, prospective study was conducted at the Toyama City Hospital (Toyama, Japan) between March 2015 and January 2017 following the approval of the Institutional Ethics Committee (no. 2014-21). All patients provided written informed consent prior to study enrollment. All study procedures were performed in accordance with the 1964 Declaration of Helsinki and its later amendments.

Patients and treatments. Patients aged $\geq 20$ years, with endoscopically diagnosed RE on the modified LA classification grade (3) between A and D were recruited for the present study. RE refractory to PPIs was defined as patients who had a Frequency Scale for the Symptoms of GERD (FSSG) (20) total score of $\geq 8$ after $\geq 8$ weeks of treatment with standard doses of PPIs (rabeprazole $10 \mathrm{mg}$ once daily, omeprazole $20 \mathrm{mg}$ once daily, esomeprazole $20 \mathrm{mg}$ once daily or lansoprazole $30 \mathrm{mg}$ once daily). Patients with RE refractory to PPIs who had no endoscopic evidence of erosive esophagitis following oral administration of vonoprazan (Takeda Pharmaceutical Company Ltd., Osaka, Japan) $20 \mathrm{mg}$ once daily after breakfast for 4 weeks were eligible for inclusion in the present study Eligible patients received maintenance therapy with vonoprazan $10 \mathrm{mg}$ once daily for 24 weeks. To avoid potential bias, concomitant treatment with vonoprazan, H2-receptor antagonists, prokinetic agents, mucosal protective factor enhancing agents and anticholinergic agents was prohibited. Other pharmacological agents, namely herbal medicine and antidepressive agents, thought to interact with the study drug, were also prohibited.

Patients with serious organ dysfunctions or malignant tumors, as well as those with concomitant gastrointestinal diseases, including esophageal stricture, achalasia, eosinophilic esophagitis, inflammatory bowel disease, primary esophageal motility disorders, Zollinger-Ellison syndrome and malabsorption syndrome, were excluded from the study. Concomitant use of non-PPI drugs prior to providing informed consent was permitted as long as the dosage remained stable throughout the study period. Patient demographics and characteristics are presented in Table I.

Endoscopic assessments and endpoint. The severity of esophagitis was determined by endoscopic examination using the modified LA classification grade between $\mathrm{A}$ and $\mathrm{D}$, with $\mathrm{M}$ and $\mathrm{N}(3,21)$. This adds additional grades $\mathrm{N}$, which is defined as no apparent mucosal change, and $\mathrm{M}$, which is defined as minimal changes in the mucosa, including erythema and/or whitish turbidity (3). Healing was defined as no detectable erosive reflux (LA grade $\mathrm{N}$ or $\mathrm{M}$ ). A diagnosis of hiatus hernia was made when the retroflexed endoscope, under the condition of gastric inflation, revealed gaping esophageal lumen allowing the squamous epithelium to be viewed below (22). Atrophic gastritis was diagnosed by endoscopy using the Kimura-Takemoto endoscopic classification (C-1, C-2, C-3, O-1, O-2 and O-3) (23). Upper GI endoscopy, which was performed transorally or transnasally in an unsedated condition, was conducted at 24 weeks in order to evaluate the presence or absence of esophageal mucosal break relapse. Morning fasting gastrin levels in serum were measured at the completion of maintenance therapy with vonoprazan $10 \mathrm{mg}$ for 24 weeks, via radioimmunoassay according to a Gastrin RIA kit® produced by Fujirebio Diagnostics, Inc. (Tokyo, Japan). The primary efficacy endpoint was the endoscopic remission rates (percentage of patients with healing RE) at 24 weeks.

Symptomatic assessments and endpoint. The incidence of GERD symptoms was determined using the FSSG (20) and the gastrointestinal QoL was assessed using the Japanese version of the Gastrointestinal Symptom Rating Scale (GSRS) (24). The FSSG is a 5-point scale (never, 0; occasionally, 1; sometimes, 2; often, 3; and always, 4) that rates the frequency of 12 symptoms associated with the gastrointestinal tract, which are divided into 2 subscales: Acid reflux-associated symptoms, in which the sums of the respective scores of items 1, 4, 6, 7, 9, 10 and 12 are calculated; and dysmotility symptoms, in which the sums of the respective scores of items 2,3,5,8 and 11 are calculated. A total score of 8 points or higher is suggestive of RE/GERD (20). The GSRS questionnaire is a 7-point scoring system (no discomfort at all, 1; minimal discomfort, 2; mild discomfort, 3; moderate discomfort, 4; moderately severe discomfort, 5; severe discomfort, 6; and very severe discomfort, 7) that rates the level of daily life discomfort associate with 15 gastrointestinal tract symptoms, which are divided into 5 subscales: Reflux (heartburn and acid regurgitation), abdominal pain (abdominal pain, hunger pain and nausea), indigestion (borborygmus, abdominal distension, eructation and increased flatus), diarrhea (diarrhea, loose stools and urgent need for defecation) and constipation (constipation, hard stools and a feeling of incomplete evacuation) (24).

Patients were asked to complete the FSSG and GSRS questionnaire at 0 (the baseline), 4, 8 and 24 weeks. Symptom relief was defined as FSSG scores and GSRS scores that were similar to or lower compared with the baseline. Symptomatic relapse was assessed using acid reflux-related symptoms and defined as 3 consecutive days with moderate/severe heartburn 
Table I. Demographic and clinical characteristics for patients with healed reflux esophagitis refractory to PPIs.

\begin{tabular}{|c|c|c|c|c|}
\hline Parameter & Total $(\mathrm{n}=52)$ & FSSG $<8(n=25)$ & $\mathrm{FSSG} \geq 8(\mathrm{n}=27)$ & P-value \\
\hline Mean age (range) & $66.0(28-84)$ & $67.6(45-84)$ & $64.6(28-84)$ & 0.371 \\
\hline $\operatorname{Sex}, M / F$ & $27 / 25$ & $15 / 10$ & $12 / 15$ & 0.211 \\
\hline Mean BMI & $22.7 \pm 5.9$ & $24.5 \pm 3.6$ & $22.9 \pm 2.8$ & 0.067 \\
\hline $\mathrm{BMI} \geq 25(\%)$ & $18(34.6)$ & $11(44.0)$ & $7(25.9)$ & 0.141 \\
\hline Duration of illness, months & $12.1 \pm 10.3$ & $9.8 \pm 13.1$ & $14.2 \pm 11.9$ & 0.213 \\
\hline Previous PPI treatment, RPZ/OPZ/EPZ/LPZ & $21 / 9 / 15 / 7$ & $13 / 5 / 4 / 3$ & $8 / 4 / 11 / 4$ & 0.201 \\
\hline $\begin{array}{l}\text { Los Angeles classification grade prior to } \\
\text { switching to vonoprazan } 20 \mathrm{mg}, \mathrm{A} / \mathrm{B} / \mathrm{C} / \mathrm{D}\end{array}$ & $25 / 14 / 9 / 4$ & $10 / 8 / 5 / 2$ & $15 / 6 / 4 / 2$ & 0.724 \\
\hline Helicobacter pylori infection (\%) & $12 / 29(41.4)$ & $3 / 15(20.0)$ & $9 / 14(64.3)$ & 0.045 \\
\hline Esophageal hiatus hernia (\%) & $17(32.7)$ & $8(32.0)$ & $9(33.3)$ & 0.577 \\
\hline Atrophy of gastric mucosa (\%) & $9(17.3)$ & $4(16.0)$ & $5(18.5)$ & 0.551 \\
\hline Functional dyspepsia (\%) & $10(19.2)$ & $5(20.0)$ & $5(18.5)$ & 0.584 \\
\hline Irritable bowel disease (\%) & $13(25.0)$ & $4(16.0)$ & $9(33.3)$ & 0.131 \\
\hline Diabetes mellitus (\%) & $2(3.8)$ & $1(4.0)$ & $1(3.7)$ & 0.584 \\
\hline Hyperlipidemia (\%) & $10(19.2)$ & $4(16.0)$ & $6(22.2)$ & 0.416 \\
\hline Hypertension (\%) & $13(25.0)$ & $8(32.0)$ & $5(18.5)$ & 0.212 \\
\hline Serum gastrin, pg/ml & 1,059 & 1,189 & 930 & 0.239 \\
\hline
\end{tabular}

PPI, proton pump inhibitor; FSSG, frequency scale for the symptoms of gastroesophageal reflux disease; BMI, body mass index; RPZ, rabeprazole; OPZ, omeprazole; EPZ, esomeprazole; LPZ, lansoprazole.

and acid regurgitation during the 24-week maintenance therapy. Patients with symptomatic relapse were withdrawn from the study. Secondary endpoints evaluated the proportion of patients with symptomatic non-relapse at 24 weeks; patients reported the presence or absence of epigastric pain, postprandial fullness and early satiation, and rated the frequency, onset and severity of these symptoms. Those with postprandial fullness or early satiation more than 1 day a week and those with epigastric pain of more than mild severity at least 1 day a week for over 6 months were defined as having functional dyspepsia (FD) according to the Rome III criteria (25). Additionally, patients with abdominal pain or discomfort at least 3 days a month in the last 3 months were defined as having irritable bowel syndrome (IBS) according to the Rome III criteria.

To evaluate the symptoms of RE without esophageal erosions despite prior vonoprazan $20 \mathrm{mg}$ treatment, patients were divided into two groups; FSSG score $\geq 8$ and FSSG score $<8$. Associations between total FSSG score improvement (a decrease in total score to $\leq 8$ ) and the FSSG subscales and GSRS subscores were assessed.

H. pylori infection was evaluated based on anti- H. pylori IgG antibody titers, using a cutoff value of $10 \mathrm{U} / \mathrm{ml}$ according to the LZ Test ${ }^{\circledR}$ produced by Eiken Chemical Co., Ltd. (Tokyo, Japan).

Statistical analysis. Analyses were performed for the intention-to-treat (ITT) population. The distribution of LA classification grades prior to treatment with vonoprazan $20 \mathrm{mg}$ and following 24 weeks of maintenance therapy with vonoprazan $10 \mathrm{mg}$ were compared using the Wilcoxon signed-rank test. The FSSG and GSRS scores were compared prior to and following maintenance therapy with vonoprazan $10 \mathrm{mg}$. Results are presented as the mean \pm standard deviation or as number $(\%)$ of patients. Intergroup comparisons were performed using the $\chi^{2}$ test for categorical data and Student's t-test for continuous data. The FSSG total score following 4 weeks of treatment with vonoprazan $20 \mathrm{mg}$ (prior to maintenance therapy) was used as the response variable for the evaluation of patient demographic and clinical characteristics. Additionally, the patient demographic and clinical characteristics were also compared between the FSSG score $\geq 8$ and FSSG score $<8$ groups. Patient demographic factors used as explanatory variables were age, gender, body mass index (BMI), duration of illness, type and dose of previous PPI treatment, presence or absence of Helicobacter pylori (H. pylori) infection, presence or absence and details of gastrointestinal complications (including hiatal hernia and atrophy of gastric mucosa) and the presence or absence and details of complications (including FD, IBS, diabetes mellitus, hyperlipidemia and hypertension). Statistical analysis was performed using SPSS 16.0 software (SPSS, Inc., Chicago, IL, USA). $\mathrm{P}<0.05$ was considered to indicate a statistically significant difference.

\section{Results}

Study profile. The flow of patients through the study is presented in Fig. 1. A total of 60 patients with RE refractory to PPIs were enrolled in the present study. Of these, 52 patients with healed RE refractory to PPIs received maintenance therapy with vonoprazan $10 \mathrm{mg}$ once daily for 24 weeks. During maintenance therapy, the number of patients with symptomatic relapse was $1(1.9 \%)$ and $4(7.7 \%)$ at 4 and 8 weeks, respec- 
Table II. Changes in FSSG for individual symptoms.

\begin{tabular}{|c|c|c|c|c|c|c|c|c|c|c|}
\hline \multirow[b]{2}{*}{ Variable } & \multicolumn{5}{|c|}{ FSSG $<8$ group $(n=25)$} & \multicolumn{5}{|c|}{ FSSG $\geq 8$ group $(n=27)$} \\
\hline & 0 weeks & 8 weeks & $\mathrm{P}$-value & 24 weeks & $\mathrm{P}$-value & 0 weeks & 8 weeks & $\mathrm{P}$-value & 24 weeks & P-value \\
\hline Acid reflux-associated symptoms & $2.72 \pm 1.7$ & $1.60 \pm 1.7$ & 0.022 & $2.12 \pm 2.0$ & 0.934 & $9.26 \pm 3.2$ & $3.78 \pm 3.2$ & $<0.001$ & $3.41 \pm 4.2$ & $<0.001$ \\
\hline Dysmotility symptoms & $1.84 \pm 1.3$ & $1.32 \pm 1.7$ & 0.241 & $1.64 \pm 1.9$ & 0.933 & $6.00 \pm 3.4$ & $3.22 \pm 2.9$ & 0.002 & $2.89 \pm 3.9$ & $<0.001$ \\
\hline
\end{tabular}

FSSG, frequency scale for the symptoms of gastroesophageal reflux disease.

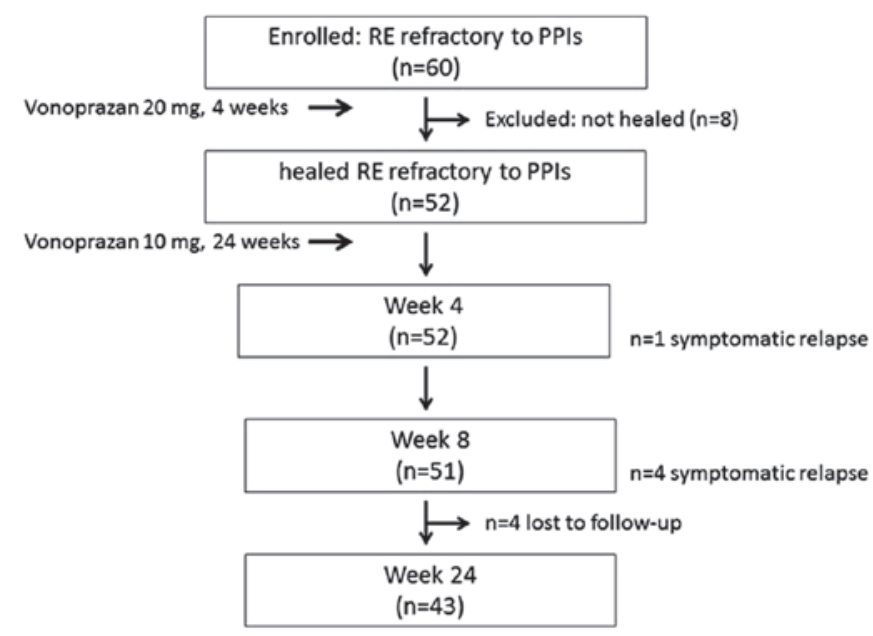

Figure 1. Study design flow chart. Symptomatic relapse was assessed as acid reflux-associated symptoms for 3 consecutive days with moderate/severe heartburn and acid regurgitation.

tively. A total of 4 patients were withdrawn because of loss to follow-up. Finally, 43 patients $(82.7 \%)$ successfully completed 24-week maintenance therapy.

Patient demographic and clinical characteristics. The eligible patients included in the present study were $52 \%$ male (Table I). To evaluate symptoms of RE without esophageal erosions despite prior vonoprazan $20 \mathrm{mg}$ treatment, patients were divided into two groups according to their FSSG score. In the total cohort of 52 patients, the mean age and BMI were 66 years $(28-84)$ and $22.7 \mathrm{~kg} / \mathrm{m}^{2}$, respectively. The LA classification prior to switching to vonoprazan $20 \mathrm{mg}$ was grade $\mathrm{A}$ in $48.1 \%$ of patients, grade B in $26.9 \%$, grade C in $17.3 \%$ and grade D in $7.7 \%$, respectively. Prior PPI treatment was administered at standard dose in all patients. The most frequently used PPI was rabeprazole $10 \mathrm{mg}(40.4 \%$ of patients), following by esomeprazole $20 \mathrm{mg}$ (28.8\%), omeprazole $20 \mathrm{mg}$ (17.3\%) and lansoprazole $30 \mathrm{mg}(13.5 \%)$. The mean duration of illness was $12.1 \pm 15.0$ months. Gastrointestinal complications were observed in $57.7 \%$ of patients (hiatus hernia $32.7 \%$, atrophic gastritis $17.3 \%$, FD $19.2 \%$ and IBS $25.0 \%$, respectively). $H$. pylori infection was significantly higher in the FSSG $\geq 8$ group compared with the $<8$ group $(\mathrm{P}=0.045$; Table $\mathrm{I})$. Otherwise, no significant differences in patient demographic and clinical characteristics were observed between the FSSG $<8$ and $\geq 8$ groups (Table I).

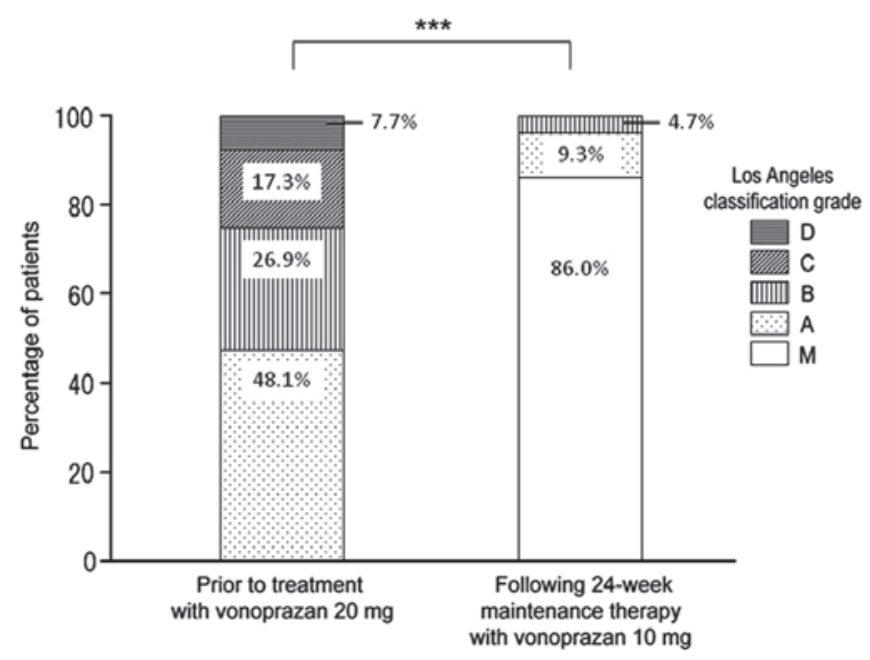

Figure 2. Distribution of Los Angeles classification grades prior to treatment with vonoprazan $20 \mathrm{mg}$ and following 24 weeks of maintenance therapy with vonoprazan $10 \mathrm{mg}$. ${ }^{* * *} \mathrm{P}<0.001$ as indicated (Wilcoxon signed-rank test).

Efficacy of maintenance therapy: Endoscopy. Following 24 weeks of vonoprazan $10 \mathrm{mg}$ maintenance therapy, 37 patients were classified as grade $\mathbf{M}$, and so the overall non-relapse rate was $86.0 \%$ Of the 6 patients who experienced esophageal mucosal break relapse, 4 were grade $\mathrm{A}$ and two were grade B. Overall, LA grades significantly improved after 24 weeks of maintenance therapy $(\mathrm{P}<0.001$; Fig. 2).

Efficacy of maintenance therapy: GERD symptoms and gastrointestinal QoL. The GERD symptoms and gastrointestinal QoL during maintenance therapy are presented in Fig. 3. The symptomatic non-relapse rate for the acid reflux-associated and dysmotility symptom scores of FSSG were 92.3 and $88.5 \%$ at 8 weeks and 86.5 and $80.8 \%$ at 24 weeks, respectively (Fig. 3). Furthermore, the symptomatic non-relapse rate for reflux, abdominal pain, indigestion, diarrhea and constipation scores of GSRS were 88.5, 82.7, 76.9, 75.0 and $69.2 \%$ at 8 weeks and $86.5,80.8,75.0,71.2$ and $76.9 \%$ at 24 weeks, respectively (Fig. 3).

Association between FSSG total score improvement and FSSG subscales. In the FSSG $\geq 8$ group, changes in the acid reflux-associated symptom scores were 9.26 $\pm 3.2,3.78 \pm 3.2$ and $3.41 \pm 4.2$ at 0,8 and 24 weeks of maintenance therapy, respectively. The scores were significantly lower at 8 and 24 weeks compared with the baseline $(\mathrm{P}<0.001$; Table II). Changes in dysmotility symptom scores were $6.00 \pm 3.4,3.22 \pm 2.9$ 
Table III. Changes in gastrointestinal symptom rating scale for individual symptoms.

\begin{tabular}{|c|c|c|c|c|c|c|c|c|c|c|}
\hline \multirow[b]{2}{*}{ Variable } & \multicolumn{5}{|c|}{ FSSG $<8$ group $(n=25)$} & \multicolumn{5}{|c|}{ FSSG $\geq 8$ group $(n=27)$} \\
\hline & 0 weeks & 8 weeks & P-value & 24 weeks & P-value & 0 weeks & 8 weeks & P-value & 24 weeks & $\mathrm{P}$-value \\
\hline Reflux & $3.96 \pm 1.7$ & $2.84 \pm 1.0$ & 0.009 & $2.96 \pm 1.2$ & 0.135 & $6.44 \pm 2.6$ & $3.81 \pm 1.7$ & $<0.001$ & $3.37 \pm 1.9$ & $<0.001$ \\
\hline Abdominal pain & $3.92 \pm 1.3$ & $3.92 \pm 1.5$ & 0.991 & $3.84 \pm 1.4$ & 0.909 & $6.81 \pm 2.9$ & $4.30 \pm 1.7$ & $<0.001$ & $4.30 \pm 2.3$ & $<0.001$ \\
\hline Indigestion & $6.83 \pm 2.7$ & $5.64 \pm 2.0$ & 0.074 & $6.20 \pm 2.3$ & 0.429 & $10.4 \pm 4.2$ & $8.15 \pm 2.8$ & 0.024 & $8.33 \pm 4.3$ & 0.044 \\
\hline Diarrhea & $4.60 \pm 2.4$ & $4.56 \pm 2.6$ & 0.956 & $4.76 \pm 2.7$ & 0.961 & $6.30 \pm 3.9$ & $5.26 \pm 3.6$ & 0.314 & $5.26 \pm 3.7$ & 0.353 \\
\hline Constipation & $5.84 \pm 3.0$ & $5.56 \pm 3.0$ & 0.744 & $5.44 \pm 3.1$ & 0.539 & $6.63 \pm 3.2$ & $5.56 \pm 1.8$ & 0.132 & $5.22 \pm 2.0$ & 0.034 \\
\hline
\end{tabular}

FSSG, frequency scale for the symptoms of gastroesophageal reflux disease.

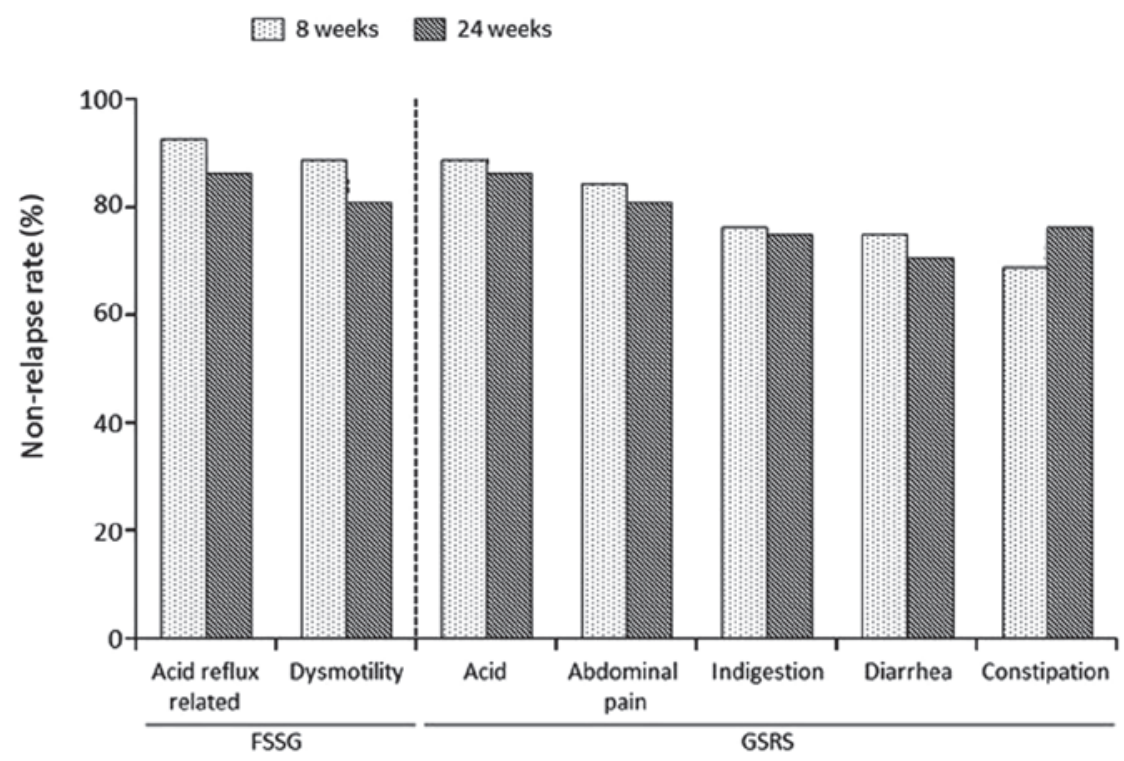

Figure 3. Cumulative non-relapse rate in FSSG and GSRS scores at 8 and 24 weeks of treatment with vonoprazan $10 \mathrm{mg}$. FSSG, frequency scale for the symptoms of gastroesophageal reflux disease; GSRS, gastrointestinal symptom rating scale.

and $2.89 \pm 3.9$ at 0,8 and 24 weeks of maintenance therapy, respectively. The scores were significantly lower at both 8 and 24 weeks compared with the baseline $(\mathrm{P}<0.01$; Table II).

In the FSSG $<8$ group, changes in the acid reflux-associated symptom scores were $2.72 \pm 1.7,1.60 \pm 1.7$ and $2.12 \pm 2.0$ at 0,8 and 24 weeks of maintenance therapy, respectively. The scores were significantly lower at 8 weeks compared with the baseline $(\mathrm{P}<0.05$; Table II). Changes in the dysmotility symptom scores were $1.84 \pm 1.3,1.32 \pm 1.7$ and $1.64 \pm 1.9$ at 0,8 and 24 weeks of maintenance therapy, respectively. No significance differences in dysmotility symptom scores of FSSG were observed during the 24-week treatment period.

Association between FSSG total score improvement and GSRS subscales. In the FSSG $\geq 8$ group, the reflux scores of GSRS were $6.44 \pm 2.6,3.81 \pm 1.7$ and $3.37 \pm 1.9$ at 0,8 and 24 weeks of maintenance therapy, respectively. The scores were significantly lower at 8 and 24 weeks after switching to vonoprazan $10 \mathrm{mg}$ compared with the baseline $(\mathrm{P}<0.001$; Table III). Abdominal pain $(\mathrm{P}<0.001)$ and indigestion $(\mathrm{P}<0.05)$ scores were significantly lower at 8 and 24 weeks compared with the baseline
(Table III). The constipation score was significantly lower at 24 weeks compared with the baseline $(\mathrm{P}<0.05$; Table III).

In the FSSG $<8$ group, the reflux scores of GSRS were $3.96 \pm 1.7,2.84 \pm 1.0$ and $2.96 \pm 1.2$ at 0,8 and 24 weeks of maintenance therapy, respectively, the scores were significantly lower at 8 weeks after switching to vonoprazan $10 \mathrm{mg}$ compared with the baseline $(\mathrm{P}<0.01$; Table III). Otherwise, no significant differences in GSRS subscale scores were observed during the 24-week treatment period (Table III).

Safety. No serious adverse events were reported during the study. Adverse events considered attributable to vonoprazan $10 \mathrm{mg}$ occurred in 1 of the 52 patients, who presented with mild abdominal fullness. This symptom improved throughout the treatment period with no intervention. The mean gastrin level was $1,059 \mathrm{pg} / \mathrm{ml}(88-3,126$; Table I).

\section{Discussion}

The results of the present study demonstrate for the first time that vonoprazan $10 \mathrm{mg}$ is a clinically 24 -week maintenance 
therapy for patients with healed RE in endoscopic and symptomatic remission irrespective of whether RE refractory to PPIs was initially healed by treatment with vonoprazan $20 \mathrm{mg}$. These results indicate that vonoprazan $10 \mathrm{mg}$ once daily prevented esophageal mucosal break relapse in $37 / 43$ patients $(86.0 \%)$.

Maintaining control of symptoms and mucosal healing is the most important goal of GERD therapy $(26,27)$. Long-term therapy with PPIs typically controls GERD more effectively than other therapies including H2-receptor antagonists and prokinetic agents (1). PPI therapy relieves symptoms and controls esophagitis in most patients with RE (28) and is recommended as the first-line treatment for GERD (1). A number of clinical trials have examined the efficacy of PPIs in GERD maintenance therapy, comparing different PPI doses and different PPIs; large-scale studies employing more $>1,000$ patients revealed that esomeprazole $20 \mathrm{mg}$ was superior to other PPIs (29-31). During a period of 6 months, esomeprazole $20 \mathrm{mg}$ once daily effectively maintained endoscopic and symptomatic remission (78.7-87.0\%) in patients who had been successfully treated for RE (29-33).

Although PPIs are recommended as the first-line treatment for GERD (1), they also possess a number of limitations, including incomplete gastric acid suppression (especially at night), inter-patient variability in efficacy due to CYP2C19 metabolism and the inconvenience of requiring mealtime dosing to ensure adequate levels of the drug during periods of $\mathrm{H}^{+}, \mathrm{K}^{+}$-ATPase activity. In addition, PPIs are slow to achieve steady state inhibition of gastric acid secretion, typically taking 3 to 5 days to achieve maximum inhibition $(34,35)$. The effect of vonoprazan $20 \mathrm{mg}$ is attributed to its potent (14-16) and rapid $(14,15)$ acid secretion suppressive effects. Vonoprazan $20 \mathrm{mg}$ was demonstrated to have a significantly greater acid-inhibitory effect compared with esomeprazole $20 \mathrm{mg}$ and rabeprazole $10 \mathrm{mg}$ in healthy Japanese subjects with the CYP2C19 extensive metabolizer genotype (15). Recent studies revealed that vonoprazan $20 \mathrm{mg}$ is an effective treatment for a majority of Japanese patients with RE refractory to PPI (17-19). Jenkins et al (14) reported that the mean efficacy rate of $10 \mathrm{mg}$ vonoprazan in achieving a gastric acid $\mathrm{pH}$ of 4.0 or higher was $63 \%$. As the mean efficacy rate of achieving gastric $\mathrm{pH} 4.0$ or higher by standard-dose PPI is $50-65 \%(15,26,36,37)$, the efficacy of vonoprazan $10 \mathrm{mg}$ may be similar to or higher than that of standard-dose PPI. However, the results of the present study revealed that 24 -week treatment with vonoprazan $10 \mathrm{mg}$ once daily successfully maintained endoscopic remission $(86.0 \%)$ and symptomatic remission $(86.5 \%)$ in patients who had been successfully treated by vonoprazan $20 \mathrm{mg}$ for RE refractory to PPIs. This may be why individual differences in the acid-suppressive effects of vonoprazan were small, as vonoprazan is mainly metabolized by CYP3A4 rather than CYP2C19 (38).

In the present study, 27 patients $(51.9 \%)$ had a total FSSG score of $\geq 8$. In the FSSG $\geq 8$ group, the mean acid reflux-associated symptom scores of FSSG and mean reflux score of GSRS improved significantly as early as 8 week after switching to vonoprazan $10 \mathrm{mg}$. However, in the FSSG $<8$ group, the mean acid reflux-associated symptom scores of FSSG and mean reflux score of GSRS were significantly lower only at 8 weeks, with no significant difference observed at the end of the 24-week maintenance period. These results suggest that vonoprazan $10 \mathrm{mg}$ may improve residual GERD symptoms in patients receiving vonoprazan $20 \mathrm{mg}$.

In the FSSG $\geq 8$ group, GSRS abdominal pain and indigestion scores were lower at 8 and 24 weeks compared with at the baseline. These results are in line with the results of a previous study in which GSRS scores were evaluated after treatment with the $\mathrm{H} 2$ blocker famotidine and the PPI omeprazole (39). It was reported that the combination treatment significantly improved the acid reflux-associated symptoms as well as the scores for abdominal pain and indigestion (39). These findings suggest that treatment with acid secretion suppressors may improve QoL associated with gastrointestinal tract symptoms other than those affecting the esophagus.

A study by Hori et al (40) indicated a high prevalence of FD and IBS in patients with GERD, which is consistent with the findings of the present study. Furthermore, Locke et al (41) conducted a study on gastrointestinal symptoms using a medical questionnaire that confirmed the presence of a complex overlap of symptoms involving the upper and lower gastrointestinal tract, including acid reflux-associated symptoms, dyspepsia symptoms, constipation and diarrhea. Similarly, the majority of patients with RE in the present study reported diverse gastrointestinal symptoms and complications.

Vonoprazan has been reported to have a favorable safety and tolerability profile $(13,14,16)$. The median morning fasting gastrin level following the administration of vonoprazan $20 \mathrm{mg}$ for 4 weeks and vonoprazan $10 \mathrm{mg}$ for 24 weeks was $1,058 \mathrm{pg} / \mathrm{ml}$, which is similar to that reported in a phase 3 clinical trial and previous studies $(16,17,19)$. Although PPI-induced hypergastrinemia does not appear to be associated with carcinoid tumor development, follow-up monitoring of gastrin levels in patients treated with vonoprazan may be necessary.

The present study has several limitations. Firstly, the study population was relatively small. Secondly, the therapeutic efficacy of vonoprazan $10 \mathrm{mg}$ in the present study is presented as a result of the evaluation of changes in a single group of patients in comparison with the baseline. Thirdly, the results of the present study are subject to potential patient bias given its open-label design. Fourthly, the presence of the CYP2C19 genotype was not investigated and 24-h gastric and esophageal $\mathrm{pH}$ monitoring was not performed. In order to confirm the results herein, multicenter investigations with a larger number of patients with RE refractory to PPIs and control subjects is required.

In conclusion, the present study demonstrated that vonoprazan $10 \mathrm{mg}$ once daily is an effective 24 -week maintenance therapy for patients with healed RE refractory to PPIs. Furthermore, vonoprazan $10 \mathrm{mg}$ may improve residual GERD symptoms in patients receiving vonoprazan $20 \mathrm{mg}$. These results suggest that vonoprazan may be a better therapy for the maintenance treatment of patients with healed RE than currently used first-line PPI therapy.

\section{References}

1. Iwakiri K, Kinoshita Y, Habu Y, Oshima T, Manabe N, Fujiwara Y, Nagahara A, Kawamura O, Iwakiri R, Ozawa S, et al: Evidence-based clinical practice guidelines for gastroesophageal reflux disease 2015. J Gastroenterol 51: 751-767, 2016. 
2. Fujiwara $Y$ and Arakawa T: Epidemiology and clinical characteristics of GERD in the Japanese population. J Gastroenterol 44: 518-534, 2009.

3. Miwa H, Yokoyama T, Hori K, Sakagami T, Oshima T, Tomita T, Fujiwara Y, Saita $\mathrm{H}$, Itou $\mathrm{T}$, Ogawa $\mathrm{H}$, et al: Interobserver agreement in endoscopic evaluation of reflux esophagitis using a modified Los Angeles classification incorporating grades $\mathrm{N}$ and M: A validation study in a cohort of Japanese endoscopists. Dis Esophagus 21: 355-363, 2008.

4. Kahrilas PJ, Shaheen NJ and Vaezi MF; American Gastroenterological Association Institute; Clinical Practice and Quality Management Committee: American Gastroenterological Association Institute technical review on the management of gastroesophageal reflux disease. Gastroenterology 135: 1392-1413, 1413.e1-1413.e5, 2008.

5. Joh T, Miwa H, Higuchi K, Shimatani T, Manabe N, Adachi K, Wada T, Sasaki M, Fujiwara Y, Hongo M, et al; ARS Research Group: Validity of endoscopic classification of nonerosive reflux disease. J Gastroenterol 42: 444-449, 2007

6. Pace F, Negrini C, Wiklund I, Rossi C and Savarino V; ITALIAN ONE INVESTIGATORS STUDY GROUP: Quality of life in acute and maintenance treatment of non-erosive and mild erosive gastro-oesophageal reflux disease. Aliment Pharmacol Ther 22: 349-356, 2005.

7. Wada T, Sasaki M, Kataoka H, Tanida S, Itoh K, Ogasawara N, Oshima T, Togawa S, Kubota E, Yamada T, et al: Efficacy of famotidine and omeprazole in healing symptoms of non-erosive gastro-oesophageal reflux disease: Randomized-controlled study of gastro-oesophageal reflux disease. Aliment Pharmacol Ther 21 (Suppl 2): 2-9, 2005.

8. Fass R: Erosive esophagitis and nonerosive reflux disease (NERD): Comparison of epidemiologic, physiologic, and therapeutic characteristics. J Clin Gastroenterol 41: 131-137, 2007.

9. Fass R, Shapiro M, Dekel R and Sewell J: Systematic review: Proton-pump inhibitor failure in gastro-oesophageal reflux disease - where next? Aliment Pharmacol Ther 22: 79-94, 2005.

10. Mizuno H, Matsuhashi N, Sakaguchi M, Inoue S, Nakada K, Higuchi K, Haruma K and Joh T: Recent effectiveness of proton pump inhibitors for severe reflux esophagitis: The first multicenter prospective study in Japan. J Clin Biochem Nutr 57: 233-238, 2015

11. Andersson $\mathrm{K}$ and Carlsson E: Potassium-competitive acid blockade: A new therapeutic strategy in acid-related diseases. Pharmacol Ther 108: 294-307, 2005.

12. Hori Y, Imanishi A, Matsukawa J, Tsukimi Y, Nishida H, Arikawa $\mathrm{Y}$, Hirase $\mathrm{K}$, Kajino $\mathrm{M}$ and Inatomi $\mathrm{N}$ : 1-[5-(2-Fluorophenyl)-1-(pyridin-3-ylsulfonyl)-1H-pyrrol-3-yl]$\mathrm{N}$-methylmethanamine monofumarate (TAK-438), a novel and potent potassium-competitive acid blocker for the treatment of acid-related diseases. J Pharmacol Exp Ther 335: 231-238, 2010.

13. Ashida K, Sakurai Y, Nishimura A, Kudou K, Hiramatsu N, Umegaki E, Iwakiri $\mathrm{K}$ and Chiba T: Randomised clinical trial: A dose-ranging study of vonoprazan, a novel potassiumcompetitive acid blocker, vs. lansoprazole for the treatment of erosive oesophagitis. Aliment Pharmacol Ther 42: 685-695, 2015.

14. Jenkins H, Sakurai Y, Nishimura A, Okamoto H, Hibberd M, Jenkins R, Yoneyama T, Ashida K, Ogama Y and Warrington S: Randomised clinical trial: Safety, tolerability, pharmacokinetics and pharmacodynamics of repeated doses of TAK-438 (vonoprazan), a novel potassium-competitive acid blocker, in healthy male subjects. Aliment Pharmacol Ther 41: 636-648, 2015.

15. Sakurai Y, Mori Y, Okamoto H, Nishimura A, Komura E, Araki T and Shiramoto M: Acid-inhibitory effect of vonoprazan $20 \mathrm{mg}$ compared with esomeprazole $20 \mathrm{mg}$ or rabeprazole $10 \mathrm{mg}$ in healthy adult male subjects - a randomised open-label crossover study. Aliment Pharmacol Ther 42: 719-730, 2015.

16. Ashida K, Sakurai Y, Hori T, Kudou K, Nishimura A, Hiramatsu N, Umegaki E and Iwakiri K: Randomised clinical trial: Vonoprazan, a novel potassium-competitive acid blocker, vs. lansoprazole for the healing of erosive oesophagitis. Aliment Pharmacol Ther 43: 240-251, 2016.

17. Hoshino S, Kawami N, Takenouchi N, Umezawa M, Hanada Y, Hoshikawa Y, Kawagoe T, Sano H, Hoshihara Y, Nomura T, et al: Efficacy of Vonoprazan for Proton Pump Inhibitor-Resistant Reflux Esophagitis. Digestion 95: 156-161, 2017.
18. Okuyama M, Nakahara K, Iwakura N, Hasegawa T, Oyama M, Inoue A, Ishizu H, Satoh $\mathrm{H}$ and Fujiwara Y: Factors associated with potassium-competitive acid blocker non-response in patients with proton pump inhibitor-refractory gastroesophageal reflux disease. Digestion 95: 281-287, 2017.

19. Iwakiri K, Sakurai Y, Shiino M, Okamoto H, Kudou K, Nishimura A, Hiramatsu N, Umegaki E and Ashida K: A randomized, double-blind study to evaluate the acid-inhibitory effect of vonoprazan (20 mg and $40 \mathrm{mg}$ ) in patients with proton-pump inhibitor-resistant erosive esophagitis. Therap Adv Gastroenterol 10: 439-451, 2017.

20. Kusano M, Shimoyama Y, Sugimoto S, Kawamura O, Maeda M, Minashi K, Kuribayashi S, Higuchi T, Zai H, Ino K, et al: Development and evaluation of FSSG: Frequency scale for the symptoms of GERD. J Gastroenterol 39: 888-891, 2004.

21. Lundell LR, Dent J, Bennett JR, Blum AL, Armstrong D, Galmiche JP, Johnson F, Hongo M, Richter JE, Spechler SJ, et al: Endoscopic assessment of oesophagitis: Clinical and functional correlates and further validation of the Los Angeles classification. Gut 45: 172-180, 1999.

22. Kinoshita Y and Adachi K: Hiatal hernia and gastroesophageal flap valve as diagnostic indicators in patients with gastroesophageal reflux disease. J Gastroenterol 41: 720-721, 2006.

23. Kimura $\mathrm{K}$ and Takemoto T: An endoscopic recognition of the atrophic border and its significance in chronic gastritis. Endoscopy 1: 87-97, 1969.

24. Hongo M, Fukuhara S and Green J: Gastrointestinal-related QOL-QOL assessment using the Japanese version of GSRS Diagn Treat 87: 731-736, 1999.

25. Drossman DA: The functional gastrointestinal disorders and the Rome III process. Gastroenterology 130: 1377-1390, 2006.

26. Dent J, Brun J, Fendrick A, Fendrick M, Janssens J, Kahrilas P, Lauritsen K, Reynolds J, Shaw M, et al: An evidence-based appraisal of reflux disease management - the Genval Workshop Report. Gut 44 (Suppl 2): S1-S16, 1999.

27. DeVault KR and Castell DO; American College of Gastroenterology: Updated guidelines for the diagnosis and treatment of gastroesophageal reflux disease. Am J Gastroenterol 100: 190-200, 2005

28. Röhss K, Lind T and Wilder-Smith C: Esomeprazole $40 \mathrm{mg}$ provides more effective intragastric acid control than lansoprazole $30 \mathrm{mg}$, omeprazole $20 \mathrm{mg}$, pantoprazole $40 \mathrm{mg}$ and rabeprazole $20 \mathrm{mg}$ in patients with gastro-oesophageal reflux symptoms. Eur J Clin Pharmacol 60: 531-539, 2004.

29. Lauritsen K, Devière J, Bigard MA, Bayerdörffer E, Mózsik G, Murray F, Kristjánsdóttir S, Savarino V, Vetvik K, De Freitas D, et al; Metropole study results: Esomeprazole $20 \mathrm{mg}$ and lansoprazole $15 \mathrm{mg}$ in maintaining healed reflux oesophagitis: Metropole study results. Aliment Pharmacol Ther 17: 333-341, 2003.

30. Labenz J, Armstrong D, Lauritsen K, Katelaris P, Schmidt S, Schütze K, Wallner G, Juergens H, Preiksaitis H, Keeling N, et al: Esomeprazole $20 \mathrm{mg}$ vs. pantoprazole $20 \mathrm{mg}$ for maintenance therapy of healed erosive oesophagitis: Results from the EXPO study. Aliment Pharmacol Ther 22: 803-811, 2005.

31. Devault KR, Johanson JF, Johnson DA, Liu S and Sostek MB: Maintenance of healed erosive esophagitis: A randomized six-month comparison of esomeprazole twenty milligrams with lansoprazole fifteen milligrams. Clin Gastroenterol Hepatol 4: 852-859, 2006.

32. Vakil NB, Shaker R, Johnson DA, Kovacs T, Baerg RD, Hwang C, D'Amico D and Hamelin B: The new proton pump inhibitor esomeprazole is effective as a maintenance therapy in GERD patients with healed erosive oesophagitis: A 6-month, randomized, double-blind, placebo-controlled study of efficacy and safety. Aliment Pharmacol Ther 15: 927-935, 2001.

33. Atug O, Giral A, Kalayci C, Dolar E, Isitan F, Oguz D, Ovunc O, Ozgur O, Soykan I, Simsek I, et al; Turkish HEMANEX Study Group: Esomeprazole in acute and maintenance treatment of reflux oesophagitis: A multicentre prospective study. Adv Ther 25: 552-566, 2008 .

34. Piche T and Galmiche JP: Pharmacological targets in gastrooesophageal reflux disease. Basic Clin Pharmacol Toxicol 97: 333-341, 2005

35. Sachs G, Shin JM and Howden CW: Review article: The clinical pharmacology of proton pump inhibitors. Aliment Pharmacol Ther 23 (Suppl 2): 2-8, 2006 
36. Shimatani T, Inoue M, Kuroiwa T, Xu J, Mieno H, Nakamura M and Tazuma S: Acid-suppressive effects of rabeprazole, omeprazole, and lansoprazole at reduced and standard doses: A crossover comparative study in homozygous extensive metabolizers of cytochrome P450 2C19. Clin Pharmacol Ther 79: 144-152, 2006.

37. Norris V, Baisley K, Dunn K, Warrington S and Morocutti A: Combined analysis of three crossover clinical pharmacology studies of effects of rabeprazole and esomeprazole on 24-h intragastric $\mathrm{pH}$ in healthy volunteers. Aliment Pharmacol Ther 25 501-510, 2007.

38. Yamasaki H,Kawaguchi N,Nonaka M, Takahashi J,Morohashi A Hirabayashi $\mathrm{H}$, Moriwaki T and Asahi S: In vitro metabolism of TAK-438, vonoprazan fumarate, a novel potassium-competitive acid blocker. Xenobiotica 47: 1027-1034, 2017.

39. Kusunoki H, Kusaka M, Kido S, Yamauchi R, Fujimura Y, Watanabe Y, Kobori M, Miwa H, Tomita T, Kin Y, et al: Comparison of the effects of omeprazole and famotidine in treatment of upper abdominal symptoms in patients with reflux esophagitis. J Gastroenterol 44: 261-270, 2009.
40. Hori K, Matsumoto T and Miwa H: Analysis of the gastrointestinal symptoms of uninvestigated dyspepsia and irritable bowel syndrome. Gut Liver 3: 192-196, 2009.

41. Locke GR III, Zinsmeister AR, Fett SL, Melton LJ III and Talley NJ: Overlap of gastrointestinal symptom complexes in a US community. Neurogastroenterol Motil 17: 29-34, 2005. Soleceperum esequi ut reperum autem es sequat.

42. Nimusa quat. Umquid maios rerrore mporum evenis eaque sequam, nissitiae rem quam quuntusdae sequo te pro corionsequid magnisint quis duntis ellicae prehent estrume ndanda nonet, ut millace aquatur aspedi dolorro conessimust, a dis im fuga. Itatemq uissusc illatem sernatu saerum qui omniam, sinum fugitium alit facescient.

(i) $\Theta$ This work is licensed under a Creative Common Attribution-NonCommercial-NoDerivatives 4.0 International (CC BY-NC-ND 4.0) License. 